\title{
Correction to: Teachers' Willingness to Use a Telepresence Robot for Consultation with Students with Autism Spectrum Disorder
}

\author{
Kimberly A. Zoder-Martell ${ }^{1} \cdot$ Margaret T. Floress $^{2} \cdot$ Maria B. Sciuchetti $^{1} \cdot$ Andrew M. Markelz $^{1} \cdot$ Laila Sayyeh $^{1}$ \\ Published online: 30 April 2021 \\ (C) California Association of School Psychologists 2021
}

\section{Contemporary School Psychology.}

https://doi.org/10.1007/s40688-021-00359-4

In the original article the name of author Maria B. Sciuchetti was misspelled. It is correct here.

Publisher's Note Springer Nature remains neutral with regard to jurisdictional claims in published maps and institutional affiliations.

The online version of the original article can be found at https://doi.org/ 10.1007/s40688-021-00359-4

Kimberly A. Zoder-Martell

kamartell@bsu.ed

1 Ball State University, 2000 W. University Ave, Muncie, IN 43036, USA

2 Eastern Illinois University, 600 Lincoln Avenue, Charleston, IL 61920, USA 